\title{
Musik Langgam Jawa untuk Menurunkan Kecemasan pada Pasien Pre-Operasi
}

\author{
Aries Triatna $^{1}$, Adi Sucipto ${ }^{2}$, Cristin Wiyani ${ }^{3}$ \\ 1,2,3 Program Studi S1 Ilmu Keperawatan, Universitas Respati Yogyakarta, Indonesia \\ Email: adisuc2410@gmail.com
}

\begin{abstract}
Javanese Style Music to Reduce Anxiety Level in Patients Pre-Operation. The most common response by pre-operative patients is anxiety. The results of research on the incidence of anxiety in pre-operative patients in RS PKU Yogyakarta mentioned that $60 \%$ of patients experience anxiety from mild to severe level (Wuryani, 2015). There are several ways to reduce anxiety, one of them is by giving music therapy. Based on the result of interviews with five patients who were going to have an operation, the patients expressed that they were anxious because they were afraid of the operation and that was worried if the operation may fail. To determine whether three is an influence of listening to "Langgam Jawa" music genre on the level of anxiety of pre-operative patients at "Kasuari" room of RSPAU, dr. S. Hardjolikito. This is a quasi-experiment research which used a pre-test and post-test non-equivalent control group design. There were 30 respondents involved as samples. The samples were selected using a systematic random sampling technique. The instrument used in this research waZung's self-rating anxiety scale (SAS). The statistical test used a Wilcoxon signed rank test with an error level of 0.05 . In the control group, which was not given "langgam jawa" music, during pre-test most patients experienced medium level anxiety $(26,7 \%)$, during post-test most patients experienced medium level anxiety (60\%); in the intervention group, before "langgam jawa" music treatment was given, most patients experienced medium level of anxiety (26,7\%), after the music treatment was given, most patients experienced a medium level of anxiety $(56,7 \%)$. Based on the research result, there is a significant influence from "langgam jawa: music therapy with a $p$-value $=0.007$. There is an influence of listening to "langgam jawa" music genre on the level of anxiety of pre-operative patients at "Kasuari" Ward, dr. S. Hardjolikito Hospital.
\end{abstract}

Keywords: Anxiety, Langgam jawa, Pre-operative

\begin{abstract}
Abstrak: Musik Langgam Jawa untuk Menurunkan Tingkat Kecemasan pada Pasien PreOperasi. Respon paling umum pada pasien pre-operasi salah satunya adalah kecemasan. Hasil riset angka kejadian kecemasan pada pasien pre-operasi di RS PKU Yogyakarta menyebutkan $60 \%$ pasien mengalami kecemasan dari tingkat ringan hingga berat (Wuryani, 2015). Ada berbagai cara untuk mengurangi kecemasan, salah satunya adalah dengan pemberian terapi musik. Berdasarkan hasil wawancara terhadap lima orang pasien yang akan menjalani operasi, pasien mengatakan merasa cemas karena takut saat dioperasi dan takut operasinya gagal. Mengetahui pengaruh mendengarkan musik langgam jawa terhadap tingkat kecemasan pada pasien pre-operasi di ruang Kasuari RSPAU dr. S. Hardjolukito. Jenis Penelitian yang digunakan adalah quasi eksperiment dengan desain pre-test and post-test non-equivalent control group. Jumlah sampel dalam penelitian ini sebanyak 30 responden. Teknik pengambilan sampel adalah systematic random sampling. Instrument dalam penelitian ini menggunakan Zung self-rating anxiety scale (SAS). Uji statistik yang digunakan adalah Wilcoxon dengan tingkat kesalahan 0,05. Pada kelompok kontrol yang tidak diberikan terapi musik langgam jawa pada pre-test sebagian besar mengalami tingkat kecemasan sedang $(26,7 \%)$, pada post-test sebagian besar mengalami tingkat kecemasan sedang $(60,0 \%)$, pada kelompok intervensi sebelum diberikan terapi musik langgam jawa sebagian besar mengalami tingkat kecemasan sedang (26,7\%), setelah diberikan terapi musik langgam jawa sebagian besar mengalami tingkat kecemasan sedang $(56,7 \%)$. Berdasarkan hasil penelitian terdapat pengaruh yang bermakna setelah diberikan terapi musik langgam jawa dengan hasil $p$-value $=0,007$. Ada pengaruh pemberian terapi musik langgam jawa terhadap tingkat kecemasan pada pasien pre-operasi di Ruang Kasuari RSPAU Dr. S. Hardjolukito.
\end{abstract}

Kata Kunci: Pre-operasi, Kecemasan, Langgam jawa 
Pembedahan yang akan dilakukan membutuhkan persiapan mental dan tergantung perawatan pre-operatif yang merupakan tahapan awal dari keperawatan perioperative. Dalam tindakan pembedahan banyak kemungkinan buruk bisa terjadi yang akan membahayakan bagi pasien, seringkali pasien menunjukan sikap yang berlebihan dengan kecemasan yang dialami. Kecemasan yang dialami biasanya terkait dengan prosedur asing yang harus dijalani dan juga ancaman terhadap keselamatan jiwa akibat segala macam prosedur pembedahan dan tindakan pembiusan (Majid, A., Judha. M., \& Istianah, U, 2011)

Respon paling umum pada pasien preoperasi salah satunya adalah kecemasan, secara mental selalu ada rasa cemas dan takut terhadap penderita yang akan menghadapi pembedahan. Dampak pada individu yang mengalami kecemasan biasanya mengemukakan keluhan. Keluhan yang sering diungkapkan antara lain cemas, merasa khawatir, firasat buruk, takut akanpikirannya sendiri, merasa tegang, gelisah, gangguan pola tidur, gangguan konsentrasi dan daya ingat. Selain itu kecemasan juga ditandai dengan beberapa gejala. Gejala-gejala tersebut pada setiap orang tidak sama, yang berarti tidak seluruhnya gejala itu harus ada (Hawari, A, 2011).

Ada berbagai cara untuk mengurangi kecemasan, salah satunya adalah dengan terapi musik. Terapi musik telah digunakan dalam lingkungan keperawatan kritis sebagai strategi untuk mengurangi kecemasan, mengalihkan, meningkatkan relaksasi, istirahat dan tidur pasien (Morton, dkk 2012). Terapi musik dirancang dengan pengenalan yang mendalam terhadap keadaan dan permasalahan klien, sehingga akan berbeda untuk setiap orang. Setiap musik juga akan berbeda maknanya untuk orang yang berbeda. Kesesuaian terapi musik akan sangat ditentukan oleh nilai-nilai individual, falsafah yang dianut, pendidikan, tatanan klinis, dan latar belakang budaya.

Pemilihan musik disesuaikan dengan kultur populasi setempat yaitu pada penelitian ini berlokasi di Yogyakarta dan mayoritas populasi adalah masyarakat dengan suku dan budaya jawa, oleh karenanya peneliti menggunakan musik langgam jawa sebagai salah satu terapi alternatif dalam menurunkan kecemasan. Musik dalam suku jawa dikenal dengan musik keroncong langgam atau biasa disebut langgam jawa.Musik langgam jawa telah menjadi bagian dari budaya musik jawa maupun budaya musik bangsa Indonesia khususnya Yogyakarta (Larasati, 2014).
Beberapa penelitian terkait tentang terapi musik salah satunya dari Faradisi, F (2012) yang menggunaan terapi musik khususnya Terapi Murotal dan Terapi Musik Klasik dalam menurunkan kecemasan pasien pra operasi. Pada penelitian ini, peneliti menggunkan terapi musik langgam jawa dikarenakan populasi yang digunakan dalam penelitian ini adalah masyarakat jawa yang sudah familiar dengan musik langgam jawa. Selain itu, musik langgam jawa sudah lama digunakan di Rumah Sakit Hardjolukito dalam menyambut pasien di Poli Rawat Jalan. Musik langgam jawa merupakan salah satu jenis musik yang memiliki karakteristik musik yang cenderung slow dan arti lirik yang dalam sehingga terapi musik langgam jawa dapat memberikan efek psikologis

Terapi musik juga diharapkan dapat membantu mengatasi stress, dan meringankan rasa sakit. Peran musik dalam terapi tentunya bukan seperti obat yang dapat dengan segera menghilangkan rasa sakit (Djohan, 2006). Pemilihan musik disesuaikan dengan kultur populasi yaitu pada penelitian ini berlokasi di Yogyakarta dan mayoritas populasi adalah masyarakat dengan suku dan budaya jawa. Musik dalam suku jawa dikenal dengan musik keroncong langgam atau biasa disebut langgam jawa.Musik langgam jawa telah menjadi bagian dari budaya musik jawa maupun budaya musik bangsa Indonesia (Larasati, S, 2014).

Berdasarkan studi pendahuluan yang dilakukan pada tanggal 24 Desember 2016 di RSPAU dr. S. Hardjolukito, pasien yang dilakukan operasi pada Januari-Oktober 2016 sebanyak 5005 pasien. RSPAU dr. S. Hardjolukito mempunyai tiga ruang bedah yaitu Camar, Kasuari, dan Kutilang. Jumlah pasien yang dilakukan operasi pada bulan November 2016 di ruang Kutilang sebanyak 66 pasien, di ruang Kasuari sebanyak 177 pasien, dan di ruang Camar sebanyak 207 pasien. Hasil wawancara pada lima pasien dengan suku jawa yang akan menjalani operasi di ruang kasuari dan camar.

Dari lima pasien tersebut, kelima pasien mengatakan merasa cemas ketika akan menjalani operasi, dan pasien terlihat gelisah. Kecemasan pasien berbagai macam seperti takut akan sakit saat dioperasi, takut operasinya gagal. Lima pasien yang dilakukan wawancara juga mengatakan sering mendengar musik langgam jawa ketika dirumah sembari istirahat, pasien juga mengatakan nyaman dan merasa rileks ketika mendengarkan musik. 


\section{METODE}

Jenis penelitian yang digunakan adalah quasi eksperiment.Penelitian ini menggunakan desain pre-test and post-test non-equivalent control group. Penelitian ini dilakukan pada bulanMaret sampai dengan April 2017 di Ruang Kasuari RSPAU dr. S. Hardjolukito dengan jumlah sampel 30 responden yang terdiri dari 15 responden kelompok intervensi dan 15 responden kelompok kontrol. Teknik pengambilan sampel yang digunakan dalam penelitian ini menggunakan systematic random sampling. Tujuan Penelitian ini adalah untuk mengetahui pengaruh mendengarkan musik langgam jawa terhadap tingkat kecemasan pasien pre-operasi. Kriteria inklusi dalam penelitian ini adalah pasien dengan usia 17-55 tahun, pasien dengan tingkat pendidikan minimal Sekolah Menengah Pertama (SMP), Pasien yang sehari sebelum menjalani operasi, pasien yang pertama kali menjalani operasi, pasien dengan pembedahan mayor, dan pasien yang bersedia menjadi responden. Sedangkan kriteria inklusi dalam penelitian ini adalah pasien yang mengalami gangguan pendengaran, dan pasien yang tidak menyukai musik langgam jawa.

\section{HASIL}

Tabel 1. Karakteristik Responden Penelitian

\begin{tabular}{lrr}
\hline Karakteristik Responden & f & \% \\
\hline Umur & & \\
Remaja akhir & 7 & 23.3 \\
Dewasa awal & 5 & 16.7 \\
Dewasa akhir & 8 & 26.7 \\
Lansia awal & 10 & 33.3 \\
\hline Jenis kelamin & & \\
Laki - laki & 9 & 30.0 \\
Perempuan & 21 & 70.0 \\
\hline Tingkat pendidikan & & \\
PerguruanTinggi & 1 & 3.4 \\
SMA & 13 & 43.3 \\
SMP & 16 & 53.3 \\
\hline
\end{tabular}

Tabel 2. Tingkat Kecemasan pada Kelompok Kontrol

\begin{tabular}{lrrrrr}
\hline \multirow{2}{*}{ Tingkat } & \multicolumn{2}{c}{ Pre-test } & \multicolumn{3}{c}{ Post-test } \\
\cline { 2 - 6 } Kecemasan & f & \% & f & \% & Total \\
\hline Ringan & 4 & 13.3 & 2 & 6.7 & 20.0 \\
\hline Sedang & 8 & 26.7 & 10 & 33.3 & 60.0 \\
\hline Berat & 3 & 10.0 & 3 & 10.0 & 20.0 \\
\hline
\end{tabular}

Tabel 3. Tingkat Kecemasan pada Kelompok Intervensi

\begin{tabular}{lrrrrr}
\hline \multirow{2}{*}{ Tingkat } & \multicolumn{3}{c}{ Pre-test } & \multicolumn{3}{c}{ Post-test } \\
\cline { 2 - 6 } Kecemasan & f & $\%$ & f & \% & Total \\
\hline Ringan & 0 & 0.0 & 4 & 13.3 & 13.3 \\
\hline Sedang & 8 & 26.7 & 9 & 30.0 & 56.7 \\
\hline Berat & 7 & 23.3 & 2 & 6.7 & 30.0 \\
\hline
\end{tabular}

Tabel 4. Uji Pengaruh Tingkat Kecemasan pada Kelompok Kontrol dan Intervensi

Test Statistik

\begin{tabular}{lr}
\hline Kelompok & $\boldsymbol{p}$-value \\
\hline Intervensi & 0,007 \\
\hline Kontrol & 0.458 \\
\hline
\end{tabular}

Tabel 5. Uji Perbandingan antara Kelompok Intervensi dan Kelompok Kontrol

\begin{tabular}{lrr} 
Kelompok & Peringkat & \multicolumn{1}{c}{$\boldsymbol{p}$-value } \\
\hline Intervensi & 14.27 & 0.370 \\
\cline { 1 - 2 } Kontrol & 16.73 & \\
\hline
\end{tabular}

\section{PEMBAHASAN}

\section{Karakteristik Responden Penelitian}

Ada beberapa faktor yang dapat mempengaruhi tingkat kecemasan pada pasien pre-operasi di RSPAU Dr. S. Hardjolukito diantaranya: usia, jenis kelamin, dan tingkat pendidikan. Berdasarkan distribusi frekuensi karakteristik responden pada tabel 1 diketahui bahwa sebagian besar pada umur lansia awal (4655 tahun) yaitu sebanyak 10 orang $(33,3 \%)$. Menurut Morton, et al. (2012) pada usia lanjut rentan terjadi beberapa perubahan-perubahan pada sistem tubuh, seperti sistem persarafan, sistem pendengaran, sistem penglihatan, sistem muskuloskeletal, sistem perkemihan, sistem endokrin, sistem reproduksi, dan sistem gastrointestina. Perubahan-perubahan pada beberapa sistem tersebut dapat membuat lansia rentan terkena penyakit dan diharuskan untuk dilakukan operasi.

Usia merupakan salah satu faktor yang dapat mempengaruhi kecemasan. Lansia adalah tahap akhir dari perkembangan manusia, usia lanjut dapat dikatakan sebagai usia emas karena tidak semua orang dapat mencapai usia lanjut. Pengalaman hidup yang banyak pada lansia dapat mempengaruhi kecemasan. Hal ini berbanding terbalik dengan yang dikemukakan teori yang mengatakan bahwa semakin tua usia seseorang maka semakin banyak pengalaman yang dimiliki dikehidupanya (Kuraesin, 2009). Kematangan dalam proses berfikir pada individu yang berumur lebih tua memungkinkan untuk 
menggunakan mekanisme koping yang baik dibandingkan dengan kelompok umur anak-anak. Selain usia, jenis kelamin juga dapat mempengaruhi kecemasan (Stuart, G. W. Laria, 2005).

Jenis kelamin merupakan salah satu faktor yang dapat mempengaruhi kecemasan. Berdasarkan distribusi frekuensi karakteristik responden pada tabel 1 diketahui bahwa sebagian besar pada jenis kelamin perempuan yaitu sebanyak 21 orang $(70,0 \%)$. Hasil penelitian ini didukung oleh penelitian sebelumnya yang mengatakan bahwa wanita lebih rentan mengalami kecemasan dibandingkan laki-laki, karena laki-laki lebih aktif dan eksploratif, sedangkan perempuan lebih sensitif (Kuraesin, 2009). Hal ini sesuai dengan penelitian sebelumnya $55,6 \%$ perempuan mengalami kecemasan. Selain itu, tingkat pendidikan juga dapat mempengaruhi kecemasan (Qulsum, A., \&Meikawati, W, 2012).

Tingkat pendidikan merupakan salah satu faktor yang dapat mempengaruhi kecemasan. Seseorang dengan pendidikan tinggi dapat lebih baik menggunakan koping sehingga memiliki tingkat kecemasan yang lebih rendah dibanding dengan seseorang yang berpendidikan rendah (Kuraesin, 2009). Berdasarkan distribusi frekuensi karakteristik responden pada tabel 1 diketahui bahwa sebagian besar pada tingkat pendidikan SMP sebanyak 16 orang $(53,3 \%)$. Hasil penelitian ini didukung oleh penelitian sebelumnyayang menyatakan ada hubungan signifikan antara tingkat pendidikan rendah dengan tingkat kecemasan, individu dengan tingkat pendidikan rendah beresiko 0,274 kali mengalami kecemasan dibandingkan dengan individu dengan tingkat pendidikan yang lebih tinggi (Kuraesin, 2009).

\section{Pengaruh Tingkat Kecemasan pada Kelompok Kontrol dan Intervensi}

Berdasarkan tabel 3 diketahui bahwa pada kelompok intervensi sebelum diberikan terapi musik langgam jawa sebagian besar mengalami tingkat kecemasan sedang dengan jumlah 8 orang $(26,7 \%)$, sedangkan setelah diberikan terapi musik langgam jawa sebagian besar mengalami tingkat kecemasan sedang dengan jumlah 9 orang $(30,0 \%)$.

Kecemasan sedang yang dialami pasien/individu dapat mempersempit persepsi individu. Individu dengan kecemasan sedang dapat mengalami perhatian yang selektif namun dapat berfokus pada lebih banyak area jika diarahkan untuk melakukannya (Stuart, Gail ,W, 2005).

Kecemasan merupakan sinyal psikofisiologis yang menandakan respon stres dimulai, setiap stres yang mengancam rasa keutuhan, ketahanan, keamanan, dan keadaan. Kecemasan suatu perasaan tidak nyaman yang muncul sebelum tanda fisiologis dan perilaku (Morton, P. G., Fontaine, D. K., Hudak, M. C., \& Gallo, B. M, 2012). Kecemasan juga merupakan konflik yang tidak disadari mengenai keyakinan, nilai, krisis situasional, maturasi ancaman diri sendiri, penyakit yang dipersepsikan sebagai ancaman kehidupan (Lubis, L. N., \& Pieter, H. Z, 2010).

Dari hasil penelitian, pada kuesioner tingkat kecemasan, skor tertinggi yang mendukung beratnya kecemasan adalah faktor gangguan fisik. Dalam penelitian ini, faktor gangguan fisik dapat mempengaruhi tingkat kecemasan karena penelitian ini dilakukan pada pasien pre-operasi. Hasil wawancara dengan sebagian besar pasien yang akan menjalani operasi mengatakan merasa cemas ketika akan menjalani operasi, dan pasien terlihat gelisah. Pasien mengatakan kecemasan yang dialami dikarenakan oleh beberapa hal seperti takut akan sakit saat dioperasi, dan takut operasinya gagal. Kecemasan yang dialami ditandai dengan beberapa gejala seperti ketegangan motorik, hiperaktivitas saraf otonom, rasa khawatir, dan kewaspadaan berlebih. Gejala-gejala tersebut tidak sama pada setiap orang, yang berarti tidak seluruhnya gejala tersebut harus ada disetiap orang (Hawari, A 2011).

Pada tabel 4 menunjukan hasil pengujian pengaruh terapi musik langgam jawa terhadap tingkat kecemasan pada pasien pre-operasi kelompok intervensi terdapatpengaruh yang bermakna antara sebelum diberikan terapi musik langgam jawa. Banyak faktor yang mempengaruhi tingkat kecemasan seseorang, diantaranya adalah usia, jenis kelamin, dan tingkat pendidikan. Faktor usia dapat mempengaruhi kecemasan, semakin tua usia seseorang maka semakin banyak pengalaman yang dimiliki dikehidupanya. Kematangan dalam proses berfikir pada individu yang berumur lebih tua memungkinkan untuk menggunakan mekanisme koping yang baik dibandingkan dengan kelompok umur anak-anak. Jenis kelamin dapat juga mempengaruhi kecemasan, berdasarkan penelitian sebelumnya yang mengatakan bahwa wanita lebih rentan mengalami kecemasan dibandingkan laki-laki, karena laki-laki lebih aktif dan eksploratif, sedangkan perempuan lebih sensitif. Hal ini juga 
sesuai dengan penelitian sebelumnya yang menyatakan $55,6 \%$ perempuan mengalami kecemasan. Selain usia dan jenis kelamin, faktor tingkat pendidikan juga merupakan salah satu faktor yang mempengaruhi kecemasan, seseorang dengan pendidikan tinggi dapat lebih baik menggunakan koping sehingga memiliki tingkat kecemasan yang lebih rendah dibandingkan dengan seseorang yang berpendidikan rendah (Stuart, G. W. Laria., 2005).

Terapi musik langgam jawa memberikan pengaruh terhadap penurunan tingkat kecemasan antara sebelum dan setelah diberikan dapat terlihat pada Tabel 4. Hal tersebut disebabkan karena efek dari musik dapat mempengaruhi stimulasi atau relaksasi. Hal ini senada dengan penelitian yang dilakukan oleh penelitian sebelumnya tentang "Terapi Musik dan Tingkat Kecemasan Pasien Pre-Operasi” yang mengatakan bahwa terapi musik dapat memberikan efek yang menenangkan bagi pasien, dapat mengurangi kegelisahan, membuat perasaan menjadi rileks, santai, serta dapat menstabilkan emosi (Savitri, W., Fidayanti, N., \& Subiyanto, P, 2016).

Berdasarkan tabel 5 menunjukan hasil pengujian pengaruh pada kelompok kontrol yang tidak diberikan terapi musik langgam jawa terhadap tingkat kecemasan pada pasien preoperasi tidak terdapat pengaruh yang bermakna antara hasil pengukuran sebelum dan sesudah pada tingkat kecemasan kelompok kontrol yang tidak diberikan terapi musik langgam jawa. Hasil penelitian pada pasien dengan kelompok kontrol penurunan tingkat kecemasan juga terjadi pada tingkat kecemasan ringan yaitu sebanyak 4 orang $(13,3 \%)$ menjadi 2 orang $(6,7 \%)$, pada tingkat kecemasan sedang terjadi peningkatan yaitu sebanyak 8 orang $(26,7 \%)$ menjadi 10 orang $(33,3 \%)$, dan pada tingkat kecemasan berat tidak terjadi peningkatan maupun penurunan. Dari beberapa pasien pada tingkat kecemasan sedang mengalami peningkatan diakibatkan oleh penurunan dari kecemasan ringan yaitu 13,3\% menjadi $6,7 \%$. Peningkatan kecemasan pada kelompok kontrol dikarenakan tidak diberikan terapi sehingga tidak ada respon tubuh untuk mengurangi kecemasan. Sesuai dengan penelitian sebelumnya tentang "Penurunan Tingkat Kecemasan pada Lansia Melalui Terapi Musik Langgam Jawa" yang mengatakan bahwa peningkatan kecemasan pada kelompok yang tidak diberikan terapi dapat dipengaruhi oleh adanya tekanan yang akan menyebabkan stressor lebih krisis yang dialami oleh pasien dimana perubahan keadaan yang mendadak seperti kematian atau kehilangan yang mendadak sehingga menimbulkan kecemasan (Junaidi, J., \& Noor, Z., 2010).

Hal ini membuktikan bahwa pemberian terapi musik langgam jawa dapat menurunkan tingkat kecemasan pada pasien pre-operasi. Hal tersebut dikarenakan musik langgam jawa merupakan suatu jenis musik yang memiliki kekhasan dengan gaya bernyanyi syahdu dan alunan musik yang lembut dan tidak menghentak, dan dapat memberikan efek relaksasi yang dapat menurunkan detak jantung dan tekanan darah, menurunkan tingkat rangsang dan membuat tenang (Stuart, G. W. Laria., 2005). Pendapat ini diperkuat dengan penelitian sebelumnya tentang Efektivitas Terapi Murotal dan Terapi Musik Klasik terhadap Penurunan Tingkat Kecemasan Pasien Pra Opersi di Pekalongan" mengatakan diperdengarkan musik sinyal musik akan diteruskan ke Amiglada yang merupakan area perilaku kesadaran yang bekerja di bawah sadar, sinyal kemudian diteruskan ke hipotalamus, kemudian jaras pendengaran diteruskan ke formatioretikularis sebagai penyalur implus menuju serat otonom. Serat saraf teresebut mempunyai dua sistem saraf, yaitu saraf simpatis dan parasimpatis, kedua saraf ini dapat mempengaruhi kontraksi dan relaksasi. Relaksasi dapat merangsang pusat rasa ganjaran sehingga timbul ketenangan (Faradisi, F., 2012).

Berdasarkan tabel 5 hasil pengujian perbandingan antar kelompok intervensi dan kelompok kontrol menunjukan hasil tidak ada perbedaan yang bermakna antara kelompok kontrol dan kelompok intervensi. Kelompok kontrol memiliki pengaruh yang lebih besar terhadap peningkatan tingkat kecemasan. Hal ini dibuktikan dengan kelompok intervensi mempunyai peringkat yang lebih rendah $(14,27)$ dibandingkan dengan kelompok kontrol $(16,73)$.

Hal ini dikarenakan pada kelompok kontrol tidak diberikan terapi musik yang dapat memberikan efek stimulasi dan relaksasi yang menenangkan bagi pasien, mengurangi kegelisahan, membuat perasaan rileks dan dapat menstabilkan emosi. Terapi musik merupakan salah satu upaya untuk mengurangi kecemasan pada pasien pre-operasi. Terapi musik telah digunakan dilingkungan perawatan sebagai strategi untuk mengurang kecemasan, mengalihkan dan meningkatkan relaksasi, istirahat, dan tidur (Morton, P. G., Fontaine, D. K., Hudak, M. C., \& Gallo, B. M., 2012). 


\section{SIMPULAN}

1. Karakteristik responden sebagian besar responden dalam kategori umur lansia awal, berjenis kelamin perempuan, dan sebagian besar dengan tingkat pendidikan SMP.

2. Tingkat kecemasan pada pasien pre-operasi di Ruang Kasuari RSPAU dr. S. Hardjolukito pada kelompok kontrol yang tidak diberikan terapi musik langgam jawa pada pre-test sebagian besar mengalami tingkat kecemasan sedang, pada post-test sebagian besar mengalami tingkat kecemasan sedang, pada kelompok intervensi sebelum diberikan terapi musik langgam jawa sebagian besar mengalami tingkat kecemasan sedang, setelah diberikan terapi musik langgam jawa sebagian besar mengalami tingkat kecemasan sedang.

3. Ada pengaruh pemberian terapi musik langgam jawa terhadap tingkat kecemasan pada pasien pre-operasi di Ruang Kasuari RSPAU dr. S. Hardjolukito.

4. Tidak terdapat perbedaan bermakna antara kelompok intervensi dan kelompok kontrol pada hasil post-test. Kelompok intervensi mempunyai peringkat yang lebih rendah $(14,27)$ dibandingkan dengan kelompok kontrol (16.73).

\section{DAFTAR PUSTAKA}

Djohan. 2006. Terapi Musik Teori dan Aplikasi. Yogyakarta: Galangpress.

Faradisi, F. 2012. Efektivitas Terapi Murottal dan Terapi Musik Klasik Terhadap Penurunan Tingkat Kecemasan Pasien Pra Operasi di Pekalongan. Jurnal Ilmiah Kesehatan (JIK), 5(2). Diakses pada 29 September 2016.

Hawari, A. 2011. Manajemen Stress Cemas dan Depresi. Jakarta: FKUI.

Junaidi, J., \& Noor, Z. 2010. Penurunan Tingkat Kecemasan Pada Lansia Melalui Terapi Musik Langgam Jawa. Jurnal Keperawatan Indonesia, 13(3), 195-201. http://www.jki.ui.ac.id/. Diakses pada 6 Oktober 2016.

Kuraesin, ND. 2009. Faktor-Faktor yang Mempengaruhi Tingkat Kecemasan Pasien Yang Akan Menghadapi Operasi Di RSUP Fatmawati Tahun 2009. [Skripsi]. Jakarta: Ilmu Keperawatan, Fakultas Kedokteran, Universitas Islam Negeri Syarief Hidayatullah.

http://repository.uinjkt.ac.id/dspace/bitstre

\section{SARAN}

1. Bagi Rumah Sakit

Kepada pihak Rumah Sakit RSPAU dr. S. Hardjolukito bagian Rawat Inap khususnya untuk bangsal bedah diharapkan mempunyai kebijakan agar terapi musik langgam jawa ini dapat diberikan kepada pasien-pasien yang akan menjalani operasi karena terapi musik langgam jawa mempunyai pengaruh untuk mengatasi kecemasan pasien yang akan menjalani operasi.

2. Bagi Institusi Pendidikan Kesehatan

Kepada Institusi Pendidikan Kesehatan khususnya Universitas Respati Yogyakarta diharapkan hasil penelitian ini dapat dikembangkan dan diterapkan dalam acuan sebagai referensi tambahan untuk mengurangi kecemasan dan untuk meningkatkan pengetahuan tentang terapi musik budaya lokal khususnya di bidang Keperawatan Medikal Bedah.

3. Bagi Peneliti Selanjutnya

Diharapkan bagi peneliti lain hasil penelitian ini dapat digunakan sebagai acuan dalam melakukan penelitian yang lebih lanjut tentang terapi musik lain berdasarkan latar belakang budaya dan keyakinan masingmasing responden.
am/123456789/2324/1/NYI\%20DEWI\%20 KURAESIN-FKIK.pdf. Diakses pada 3 Mei 2017.

Larasati, S. 2014. Gaya Vokal Waldjinah Pada Langgam Keroncong. [Skripsi]. Bandung: Jurusan Pendidikan Seni Musik, Fakultas Pendidikan Bahasa dan Seni, Universitas Pendidikan Indonesia. http://repository.upi.edu/12581/. Diakses pada 3 November 2016.

Lubis, L. N., \& Pieter, H. Z. 2010. Pengantar Psikologi Dalam Keperawatan. Jakarta: Kencana Prenada Media Group.

Majid, A., Judha. M., \& Istianah, U. 2011. KeperawatanPerioperatif. Edisi Pertama. Yogyakarta: Gosyen Publishing.

Morton, P. G., Fontaine, D. K., Hudak, M. C., \& Gallo, B. M. 2012. Keperawatan Kritis Pendekatan Asuhan Holistik. Edisi 8. Jakarta: EGC.

Qulsum, A., \& Meikawati, W. 2012. Perbedaan Tingkat kecemasan pada Pasien Pre Operasi Sebelum Dan Sesudah Pemberian Terapi Musik Klasik Di RSUD Tugurejo 
Semarang. [Skripsi]. Semarang: Sekolah Tinggi Ilmu Kesehatan Telogorejo.

Savitri, W., Fidayanti, N., \& Subiyanto, P. 2016. Terapi Musik dan Tingkat Kecemasan Pasien Preoperasi. Media Ilmu Kesehatan 5(1), 1-6.

http://ejournal.stikesayaniyk.ac.id.

(Diakses pada 6 Oktober 2016).
Stuart, G. W. Laria. 2005. Buku Saku Keperawatan Jiwa. Jakarta: EGC.

Wuryani, S., Fatmawati, N., \& Aprilia, R. 2015. Pengaruh Terapi Relaksasi Masase Punggung Terhadap Penurunan Tingkat Kecemasan pada Pasien Pre-Operasi Bedah Mayor Di Smc Rs Telogorejo. Jurnal Ilmu Keperawatan dan Kebidanan, 1(1). 